\title{
Electrochemical Studies of Chlorine Containing Silanes
}

\author{
J. Mark A. Hoddenbagh, ${ }^{\text {a }}$ Daniel A. Foucher, ${ }^{\text {b* }}$ D. J. Worsfold ${ }^{c \dagger}$
}

aPresident's Office, Cumberland College, 503 - 2nd St. E., P.O. Box 2225. Nipawin, Saskatchewan, Canada S0E 1E0

${ }^{\mathrm{b} C h e m i s t r y}$ and Biology, Ryerson University, 350 Victoria Street, Toronto, Ontario, Canada M5B 2K3

'Institute for Environmental Research, National Research Council of Canada, Ottawa, Ontario, Canada K1A 0R9

${ }^{\dagger}$ Deceased

\begin{abstract}
The reduction potentials of a series of mono-, di- and trichloro alkyl and aryl substituted silanes was investigated by cyclic voltammetry. It was shown that chlorosilanes can be reduced in two one electron steps at potentials more positive than $-1 \mathrm{~V}$ vs SCE. The solvent type (THF, MeCN), silane type and polymerization and electrolyte concentration were varied and found to greatly impact the reduction potential.
\end{abstract}

\section{Introduction}

Several electrochemical studies of silanes with various numbers of $\mathrm{Si}-\mathrm{Cl}$ bonds have been reported over the last 40 years. $^{1-9}$ Several authors have suggested that these reductions occur at moderate potentials $(-0.4$ to $-0.6 \mathrm{~V})$ versus a saturated calomel electrode (SCE), ${ }^{2,3,9}$ while others suggest that reduction potentials are possibly even lower (-2.0V vs SCE). ${ }^{1,4-8}$ The more positive potentials have been suggested to derive from reduction of $\mathrm{HCl}$ formed by the hydrolysis of the chlorosilanes by residual water in organic solvents used in these studies. ${ }^{4-6,8}$

A knowledge of the true reduction potentials has great implication for both chemical and electrochemical polymerization reactions of dichlorosilanes to polysilanes. These main group polymers are of great interest in areas as diverse as non-linear optical materials, as preceramic 
materials for $\mathrm{SiC}$ formation and for use in microlithography. Comprehensive reviews of polysilanes can be found elsewhere. ${ }^{10}$ To date electropolymerization reactions have been attempted with a number of chlorine containing silanes. ${ }^{7,11-17}$ Constant current and high potential electrolyses have been attempted, with current densities in $\mathrm{mA} / \mathrm{cm}^{2}$ range for the former and potentials near $-3 \mathrm{~V}$ vs SCE for the latter. In general cyclic, oligomeric and low molecular weight polymers are obtained in poor to moderate yields. To date, molecular weights comparable to those from Wurtz-type coupling of dichlorosilanes with alkali metals $\left(10^{3}-10^{6}\right.$ daltons) have not been reported. The electrochemical deposition of $\alpha$-silicon from $\mathrm{SiHCl}_{3}$ onto electrode surfaces has also been observed..$^{18,19}$

This current study is concerned with the determination of the reduction potentials of a series of mono-, di-, and trichloro alkyl and aryl substituted silanes (Figure 1) by cyclic voltammetry as a function of solvent, silane and electrolyte concentrations. Tetrahydrofuran (THF) and acetonitrile $(\mathrm{MeCN})$ were used as solvents while tetrabutylammonium perchlorate (TBAP) was used as the electrolyte at concentrations between 0.1-0.8 M. The results obtained are consistent with some previous reports and at variance with interpretations in others.

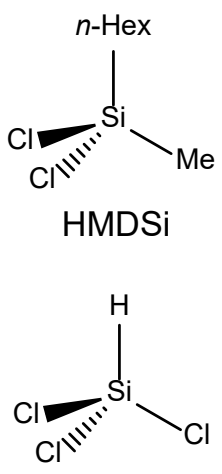

TSi<smiles>C[Si](C)(Cl)Cl</smiles>

DMDSi<smiles>C[Si](C)(C)O</smiles>

TMSi<smiles>C[Si](Cl)(Cl)c1ccccc1</smiles>

DPDSi

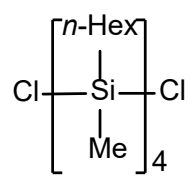

DTTSi<smiles>[Mg][SiH3]Cl</smiles>

DMSi<smiles>CC1(C)CCC[Si]1(C)Cl</smiles>

$\mathrm{D}(\mathrm{HMSi}) 14$

Figure 1. Chlorosilanes used in this study 


\section{Experimental}

Solvents: THF was refluxed with and distilled from molten potassium using naphthalene and benzophenone as indicators of the absence of impurities. MeCN was refluxed in and distilled from $\mathrm{P}_{2} \mathrm{O}_{5}$. 1,2-Dimethoxyethane gave similar results to THF and was not used after the initial studies.

Electrolytes: TBAP (Strem) was initially recrystallized from an ethanol/water mixture and dried at $60{ }^{\circ} \mathrm{C}$ in vacuo. Analysis by IR spectroscopy confirmed the absence of water. $\mathrm{LiCl}$ and $\mathrm{LiClO}_{4}$ were also tried as electrolytes, but gave inferior results to TBAP and their use was not pursued. Tetraethylammonium chloride was used in one experiment at $1 \mathrm{mM}$ with $0.1 \mathrm{M}$ TBAP in an unsuccessful attempt to stabilize the $\mathrm{Ag} / \mathrm{AgCl}$ reference electrode.

Equipment: The cyclic voltammograms (CV) were obtained using an EG\&G Princeton Applied Research (Model 273) Potentiostat/Galvanostat. A specifically constructed electrochemical cell with three upper inlet ports leading to a flat-bottomed, cone-shaped reaction vessel was used. The chamber was encased in a glass jacket through which water was pumped to maintain a constant temperature and the solution could be stirred with a small magnetic stirrer.

Electrodes: Unless otherwise stated, all potentials are given in volts versus SCE. The working and counter electrodes were made of platinum. A large working electrode $(0.5 \mathrm{~cm} \times 1.0 \mathrm{~cm})$ was used occasionally, but most experiments were performed with a $0.90 \mathrm{~mm}$ diameter Pt wire encased in glass as it allowed the two-electron reduction to be measured (see below). The flat head of this electrode was regularly polished with 300 and 600 diamond grit sandpaper to remove any oxides and/or absorbed species.

A variety of reference electrodes were tried with varying degrees of success. $\mathrm{Ag} / \mathrm{AgCl}$ electrodes were used but their potentials drifted with time due to metathesis of the $\mathrm{Cl}^{-}$for the $\mathrm{ClO}_{4}^{-}$ 
present in solution. An SCE was used for most experiments. There was a concern that the porous ceramic plug at the electrode/solution interface would allow seepage of water into the solution leading to hydrolysis of the $\mathrm{Si}-\mathrm{Cl}$ bonds and loss of current. In practice it was found that there was no effect on the signals over the timescales of the experiments (usually less than one hour, vide infra), and that similar curves were obtained using both the $\mathrm{Ag} / \mathrm{AgCl}$ and $\mathrm{SCE}$ reference systems. The potential of the $\mathrm{Ag} / \mathrm{AgCl}$ electrode was standardized relative to the SCE by referencing both to the potential of a $5 \mathrm{mM} \mathrm{FeCp}_{2}{ }^{+/ 0}$ solution in either THF or MeCN (0.1 M TBAP).

Chemicals: The following chemicals were obtained from Petrarch: dichlorohexylmethyl silane (HMDSi), dichlorodimethylsilane (DMDSi), dichlorodiphenylsilane (DPDSi), dichloromethylphenylsilane ((DMPSi), dichloromethylsilane (DMSi) and chlorotrimethylsilane (TMSi). Trichlorosilane (TSi) was purchased from Aldrich. The silanes were distilled prior to use. Hydrochloric acid ( $\mathrm{HCl}$, Fisher) was used as received. 1,4-Dichloro-1,2,3,4-tetrahexyl1,2,3,4-tetramethylsilane (DTTSi) and Cl-(hexymethylsilane) ${ }_{\mathrm{n}}-\mathrm{Cl}$, where $\mathrm{n}_{\mathrm{av}}=14\left(\mathrm{D}(\mathrm{HMSi})_{14}\right)$ were synthesized by chlorination of a high molecular weight polymer with $\mathrm{Cl}_{2}$ or $\mathrm{SOCl}_{2}$ in $\mathrm{CCl}_{4}{ }^{20,21}$ The original polymer was made by a Wurtz-type coupling reaction of HMDSi with Na and had a biomodal distribution with $\mathrm{M}_{\mathrm{w}}=10^{5}$ and $10^{6}$ daltons versus polystyrene standards. ${ }^{22}$

General Procedure: A typical experiment entailing dissolving TBAP in solvent to give the desired concentration. Dry $\mathrm{N}_{2}$ was bubbled through the solution for approximately 20 min to remove dissolved $\mathrm{O}_{2}$. The cell temperature was maintained at $25 \pm 0.2{ }^{\circ} \mathrm{C}$ throughout the experiment by means of a circulating water bath. The electrodes were connected and the CV's run under an $\mathrm{N}_{2}$ blanket. In one experiment, $0.3 \mathrm{~mL}$ of $0.1 \mathrm{M} \mathrm{HCl}_{(\mathrm{aq})}$ was mixed with $12 \mathrm{~mL}$ of $10 \mathrm{mM}$ HMDSi in MeCN (0.1 M TBAP) to determine the effect of water on the voltammograms of HMDSi. 


\section{Results and Discussion}

Typical voltammograms are shown in Figure 2 for HMDSi in MeCN, DMDSI in THF and for $\mathrm{D}(\mathrm{HMSi})_{14}$ in THF. The salient features of the silane curves include a prominent cathodic peak with a shoulder on the positive potential side, and a pronounced anodic peak with a shoulder at negative potentials, indicative of two redox processes. Reduction potentials, $E_{1 / 2}$ values, for a number of mono-, di- and trichlorosilanes were determined in MeCN (Table 1) and THF (Table 2) at various concentration of silane and TBAP. For a number of silanes clear peak resolution of the two redox processes in THF was not possible but the peaks observed are noted in Table 2. For the $\mathrm{HCl}_{(\mathrm{aq})}$ scan, only a single redox process was observed.

In $\mathrm{MeCN}$ there was a small effect on [HMDSi] on both $\mathrm{E}_{\frac{1}{2} / 2}^{1}$ and $\mathrm{E}_{1 / 2}^{2}$ at $0.1 \mathrm{M}$ TBAP with the redox potentials moving to more negative values with increasing concentration. Increasing the ionic strength led to a positive shift of $\mathrm{E}_{1 / 2}^{2}$ while $\mathrm{E}_{1 / 2}^{1}$ remained essentially unchanged. Increasing the Si chain length from 1 to 4 gave a large positive shift of $300 \mathrm{mV}$ for $E_{1 / 2}^{1}$ and $100 \mathrm{mV} \mathrm{E} \frac{1 / 2}{2}$. The $\mathrm{E}_{1 / 2}$ value for $\mathrm{HCl}(\mathrm{aq})$ is $-0.22 \mathrm{~V}$ and is very different from those for the three silanes noted in Table 1. Thus it is reasonable to conclude that the redox peaks observed for the silanes do not arise from the hydrolysis products but are due to the dichlorosilanes. Confirmation of this conclusion comes from the effect observed when $0.1 \mathrm{M} \mathrm{HCl}_{(\mathrm{aq})}$ is added to HMDSi in MeCN. The redox peaks assignable to HMDSi slowy disappeared over 2 min with concomitant formation of a new peak assigned to $\mathrm{H}^{+}$. Given the high concentration of $\mathrm{H}_{2} \mathrm{O}$ in the $\mathrm{HCl}_{(\mathrm{aq})}$ solution, it would appear that hydrolysis of HMDSi is fairly slow and thus would affect only marginally the $i$-E curves over the time scale of the experiments. 
Table 1. Reduction Potentials for Various Chlorosilanes and $\mathrm{HCl}$ in $\mathrm{MeCN}$

\begin{tabular}{|c|c|c|c|c|c|}
\hline Silane & $\begin{array}{c}\text { [TBAP] } \\
\text { (M) }\end{array}$ & $\begin{array}{c}\text { [Silane] } \\
(\mathbf{m M})\end{array}$ & $\begin{array}{c}\mathrm{v} \\
(\mathrm{mV} / \mathrm{s})\end{array}$ & $\begin{array}{l}\mathbf{E}_{1 / 2}^{1} \\
(\mathbf{V})\end{array}$ & $\begin{array}{l}\mathbf{E}_{1 / 2}^{2} \\
(\mathrm{~V})\end{array}$ \\
\hline HMDSi & 0.1 & 5 & $100,150,200$ & $-0.13 \pm 0.01$ & $-0.41 \pm 0.02$ \\
\hline HMDSi & 0.1 & 10 & 150 & $-0.17 \pm 0.05$ & $-0.50 \pm 0.05$ \\
\hline HMDSi & 0.8 & 10 & 200 & $-0.15 \pm 0.04$ & $-0.43 \pm 0.01$ \\
\hline DMDSi & 0.1 & 10 & 100,150 & $-0.14 \pm 0.01$ & $-0.44 \pm 0.04$ \\
\hline DTTSi & 0.1 & 10 & $\begin{array}{c}150,200,300,400 \\
500,750,1000\end{array}$ & $-0.12 \pm 0.05$ & $-0.33 \pm 0.04$ \\
\hline $\mathrm{HCl}$ & 0.8 & 22 & 200 & $-0.22 \pm 0.01$ & \\
\hline
\end{tabular}



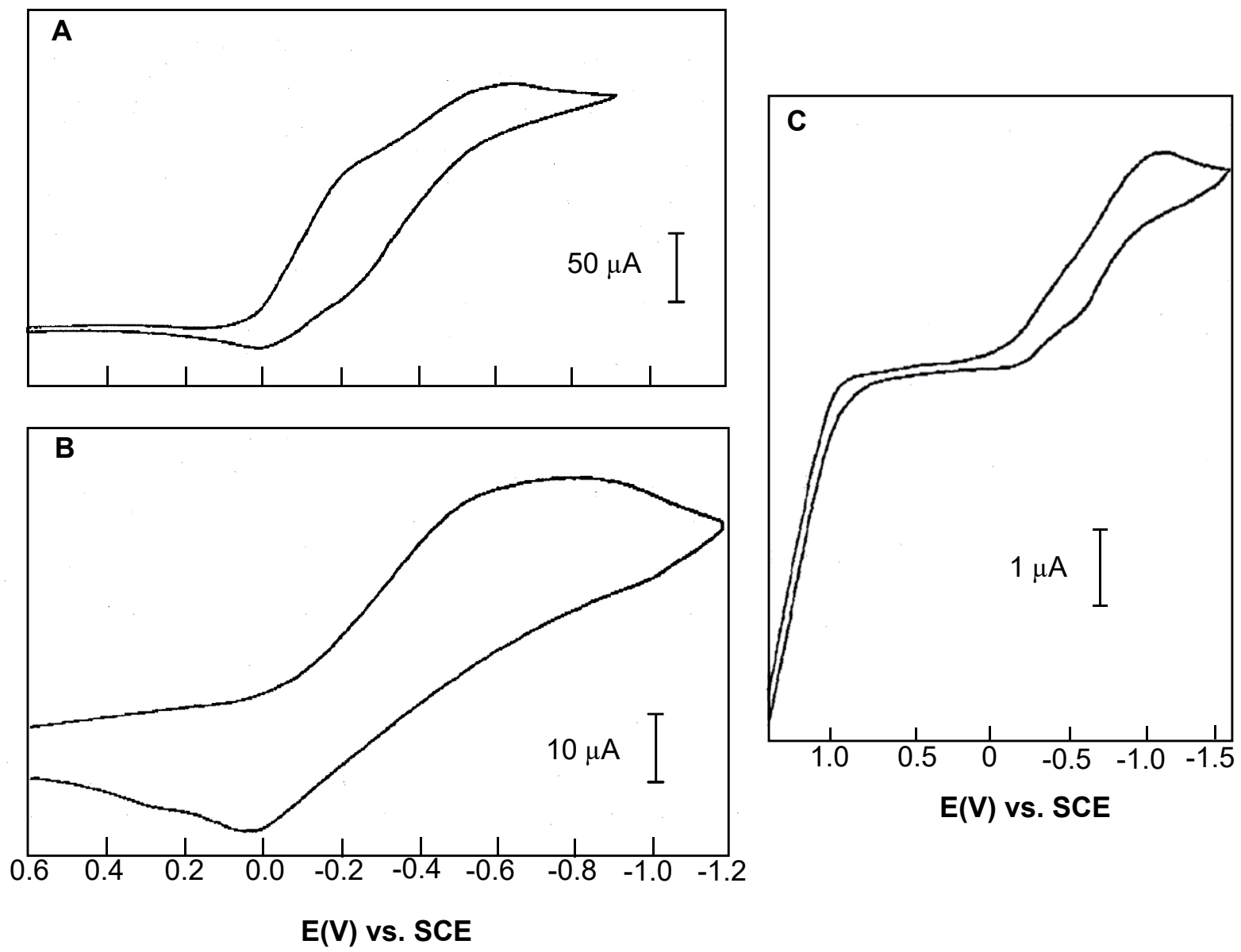

Figure 2. Cyclic voltammograms for (A) $10 \mathrm{mM}$ HMDSi in $\mathrm{MeCN}(0.1 \mathrm{M}$ TBAP, $v=150 \mathrm{mV} / \mathrm{s})$; (B) $10 \mathrm{mM} \mathrm{HMDSi}$ in THF $(0.8 \mathrm{M}$ TBAP, $v=500 \mathrm{mV} / \mathrm{s})$; and (C) $10 \mathrm{mM} \mathrm{D}(\mathrm{HMSi})_{14}$ in THF (0.1 M TBAP, $v=50 \mathrm{mV} / \mathrm{s})$.

Similar results to those obtained in MeCN were found in THF (Table 2). The major differences were the following:

(1) the shoulders were not very pronounced at lower concentrations and thus it was difficult to obtain redox potentials for all species studied;

(2) at low concentrations the reduction potentials in THF were more negative than those in MeCN. 
Table 2. Reduction Potentials for Various Chlorosilanes and $\mathrm{HCl}$ in THF

\begin{tabular}{|c|c|c|c|c|c|}
\hline Silane & $\begin{array}{c}\text { [TBAP] } \\
(\mathrm{M})\end{array}$ & $\begin{array}{c}\text { [Silane] } \\
(\mathrm{mM})\end{array}$ & $\begin{array}{c}\mathrm{v} \\
(\mathrm{mV} / \mathrm{s})\end{array}$ & $\begin{array}{l}E_{1 / 2}^{1} \\
(V)\end{array}$ & $\begin{array}{l}\mathbf{E}_{1 / 2}^{2} \\
\text { (V) }\end{array}$ \\
\hline HMDSi & 0.1 & 10 & 150 & $-0.46 \pm 0.07$ & $-0.85 \pm 0.06$ \\
\hline HMDSi & 0.8 & 5 & $50,150,200$ & $-0.09 \pm 0.02$ & $-0.37 \pm 0.01$ \\
\hline HMDSi & 0.8 & 10 & $50,150,200$ & $-0.14 \pm 0.02$ & $-0.46 \pm 0.02$ \\
\hline DMDSi & 0.8 & 10 & $100,200,500$ & $-0.09 \pm 0.01$ & $-0.41 \pm 0.01$ \\
\hline DPDSi & 0.8 & 10 & $100,200,500$ & $-0.23 \pm 0.04$ & $-0.44 \pm 0.01$ \\
\hline MPDSi & 0.8 & 10 & 100 & $\begin{array}{r}\text { cathodic peak } \\
0.7 \text {, anodi }\end{array}$ & $\begin{array}{l}\text { at } \approx-0.4 \text { and }- \\
\text { peak at }-1\end{array}$ \\
\hline DMSi & 0.8 & 10 & 200 & \multicolumn{2}{|c|}{ broad cathodic peak at -1} \\
\hline TMSi & 0.8 & 10 & 200 & $\begin{array}{l}\text { cathodic pea } \\
0.7 \text {, anodic }\end{array}$ & $\begin{array}{l}\text { at } \approx 0.5 \text { and } \\
\text { ak at } \approx 0.15\end{array}$ \\
\hline SiTC & 0.8 & 10 & $10,50,100,200$ & $-0.23 \pm 0.02$ & $-0.45 \pm 0.03$ \\
\hline DTTSi & 0.1 & 10 & 150 & $-0.43 \pm 0.04$ & $-0.89 \pm 0.02$ \\
\hline $\mathrm{D}(\mathrm{HMSi})_{14}$ & 0.1 & 10 & $50,75,100$ & $-0.36 \pm 0.04$ & $-0.85 \pm 0.03$ \\
\hline $\mathrm{HCl}$ & 0.1 & 10 & 100 & $-0.36 \pm 0.01$ & \\
\hline & 0.8 & 10 & 100 & $-0.27 \pm 0.01$ & \\
\hline
\end{tabular}

For HMDSi similar trends were observed for increasing silane and electrolyte concentrations as in MeCN. Increasing [TBAP] from 0.1 to $0.8 \mathrm{M}$ in THF had a dramatic effect on the redox potentials with $\mathrm{E}_{1 / 2}^{1}$ shifting $+300 \mathrm{mV}$ and $\mathrm{E}_{1 / 2}^{2}$ shifting $+400 \mathrm{mV}$. $\mathrm{E}_{1 / 2}$ for $\mathrm{HCl}$ also increased with increasing 
[TBAP] though the reduction potential determined was different from those observed for the silanes.

The ratio of the cathodic to anodic currents for the two redox processes were found to be greater than unity in both solvents. This suggests that there is some type of irreversibility, either chemical or electrochemical, in these systems.

The problem of adsorption of reduction products onto the Pt electrode was investigated by plotting the peak current $\left(i_{p}\right)$ versus various functions of the scan rate (v). A linear relationship of $i_{p}$ with $v$ indicates that the electron transfer reaction is occurring at an absorbed species while a linear relationship with $v^{1 / 2}$ is characteristic of electron transfer to a species in solution via diffusionlimited processes. ${ }^{23}$ Plots of $i_{p}$ versus $v^{1 / 2}$ were linear as shown in Figure 3, demonstrating that the observed redox activity was due to solvated species and not adsorbed ones. It had been previously observed that electrolysis of chlorosilanes at negative potentials leads to adsorption of reduction products onto the working electrode ${ }^{3}$ and that holding the Si contaminated electrode at positive potentials allowed for desorption of the Si containing layer. In this work it was noticed that after 5-10 scans the electrode response degraded and the peaks were shifted negatively. Electrolysis for several minutes at $\mathrm{E}=+1 \mathrm{~V}$ allowed for the original electrode response to be regenerated. Thus it appears that there is redox activity at potentials above $-1 \mathrm{~V}$ ascribable to chlorosilanes and that the observed curves were not due to adsorbed species but to solvated ones. 


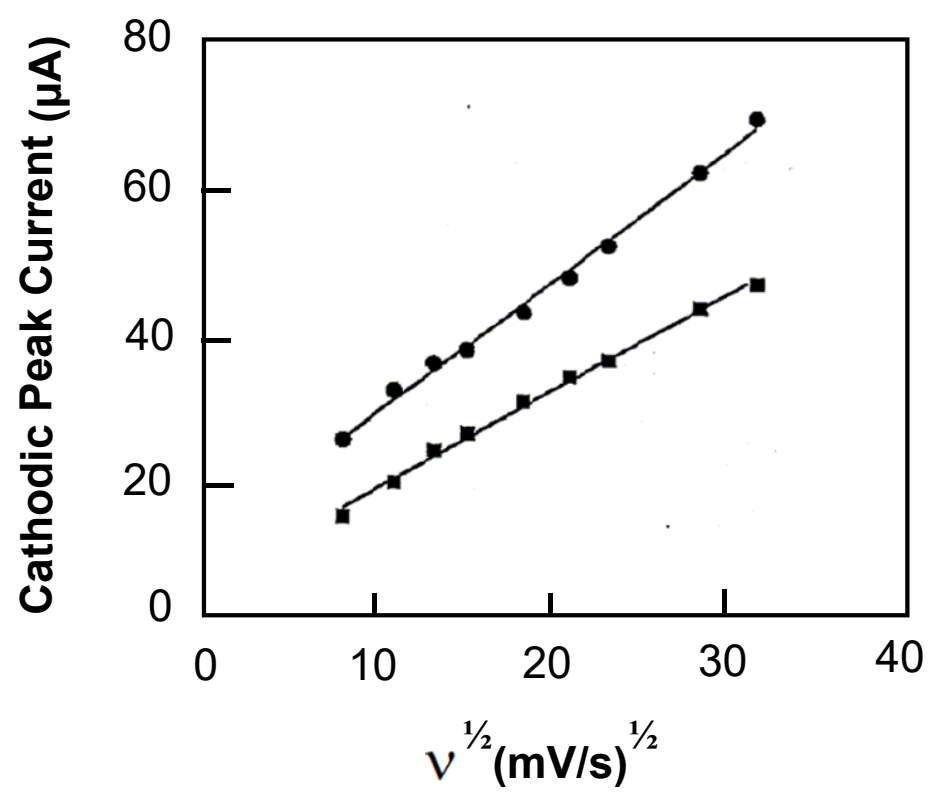

Figure 3. Scan rate ${ }^{1 / 2}\left(v^{1 / 2}\right)$ vs. cathodic peak current $\left(i_{p c}\right)$ for $10 \mathrm{mM}$ HMDSi in $\mathrm{MeCN}(0.1 \mathrm{M}$ TBAP); $i_{p c}{ }^{1}$ and $\bullet i_{p c}{ }^{2}$.

In summary, the important features are that:

(1) for some of the chlorosilanes two redox processes are observable in MeCN and THF,

(2) these redox processes are not due to products of the hydrolysis of the Si-Cl bonds,

(3) the redox processes are somewhat irreversible,

(4) reduction is energetically easier in more polar solvents,

(5) high electrolyte concentrations facilitate reductions,

(6) increasing silane concentrations leads to more difficult reductions, and

(7) increasing chain length causes $\mathrm{E}_{1 / 2}^{1}$ in THF and both $\mathrm{E}_{1 / 2}^{1}$ and $\mathrm{E}_{1 / 2}^{2}$ values in $\mathrm{MeCN}$ to become smaller at constant TBAP and silane concentration ( $0.1 \mathrm{M}$ and $10 \mathrm{M}$ respectively).

The aforementioned observations can best be discussed in the framework of the following equations: 


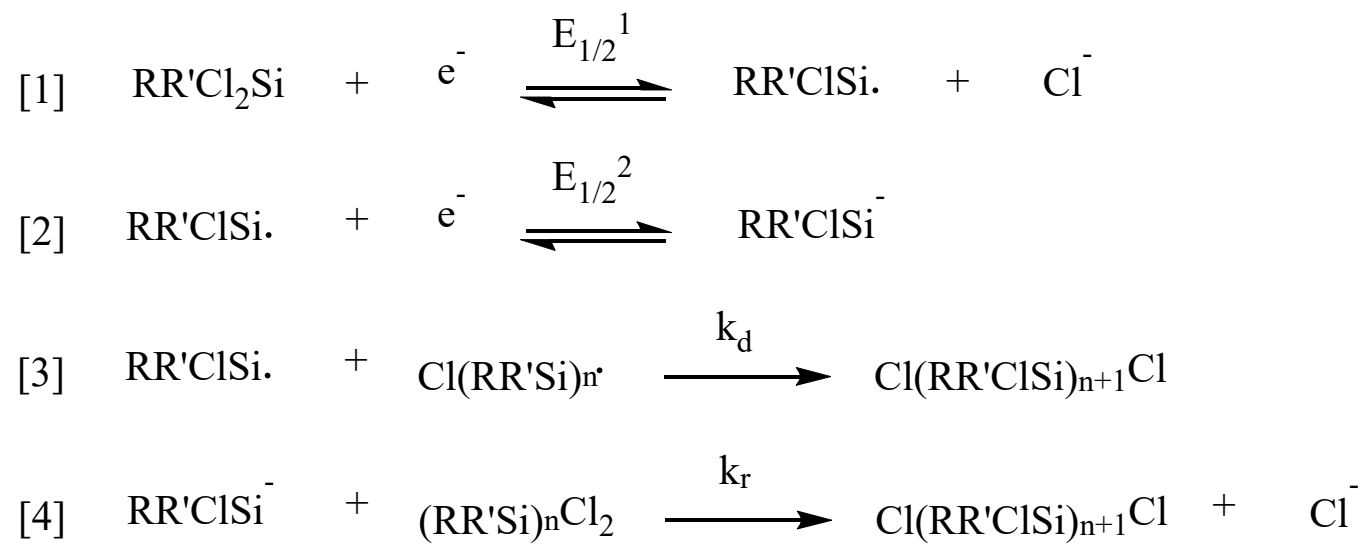

The two redox processes observed are due to Equations [1] and [2]. In [1] the starting compound is reduced to the neutral radical and $\mathrm{Cl}^{-}$. Subsequent reduction of the radical leads to the anion as shown in Equation [2].

The hypothesis that the observed electrochemical behaviour arises from hydrolysis products has already been discussed. From the rate of disappearance of the HMDSi signal on addition of $0.1 \mathrm{M} \mathrm{HCl}$, it can estimated that the HMDSi rate of hydrolysis with $\mathrm{H}_{2} \mathrm{O}$ of $\approx 10^{-2}$ $\mathrm{M}^{-1} \cdot \mathrm{s}^{-1}$. At $0.01 \mathrm{M} \mathrm{H}_{2} \mathrm{O}$ in THF the half-life of $0.010 \mathrm{M}$ HMDSi would be on the order of $2 \mathrm{~h}$. This rate of hydrolysis is consistent with those reported in the literature for trialkylchlorosilanes. ${ }^{24,25}$ In these experiments hydrolysis appears to be of minor importance.

The irreversibility observed may be due to electrochemical (sluggish heterogeneous electron transfer) or chemical (subsequent chemical reactions) effects. Estimates of the heterogeneous rate constants for a number of chlorosilanes were made using a modification of the Randel-Sevich equation. ${ }^{26}$ Values of $\approx 10^{-3} \mathrm{~cm} \cdot \mathrm{s}^{-1}$ were obtained, indicative of sluggish electron transfer but not sufficiently slow to contribute to the irreversibility. Chemical reactions (Electrochemical type mechanisms) such as those given in Equations [3, 4] must be responsible for the irreversibility. Equation [3] is a radical coupling reaction to extend the $\mathrm{Si}$ chain by one $\mathrm{Si}$ 
unit. Equation [4] can be thought of being a nucleophilic displacement of $\mathrm{Cl}^{-}$by the $\mathrm{Si}^{-}$moiety. Alternatively, Equation [4] may be viewed as a two-step process with initial electron transfer from the anion to the neutral silane, generating two neutral radicals, which then couple. Interestingly, the lifetimes of the radicals and anions are long enough to allow for their detection on the oxidative scan. This contrasts with the analogous chlorohydrocarbon species where only reductive currents are seen unless there is considerable stabilization by other substituents as seen in the triphenyl species. In fact, many alkyl chlorides are not electrochemically reducible. ${ }^{27}$ Thus it seems that $\mathrm{Si}$ is better at stabilizing radicals and anions than $\mathrm{C}$.

The solvent effect on the ease of reduction is not unexpected in view of the more favourable solvation energies polar solvents such as $\mathrm{MeCN}$ exert on radicals and ions as opposed to the unfavourable ones from less polar solvents such as THF. As the [TBAP] in THF is increased, the amount of dissociated species also increases and thus more ions are available for stabilizing the silane intermediates. The increasing ease of reduction with increasing electrolyte concentration can be attributed to a "pseudo-solvation" effect where the electrolyte ions help to stabilize the silane radicals and anions through the formation of complexes such as ion-pairs.

As the silane concentration is decreased the reduction becomes easier, which may be due to mass transfer effects. At higher HMDSi concentrations there will is more HMDSi at the solventelectrode interface and thus less dissociated electrolyte. Therefore, there will be a lower concentration of TBAP at the electrode and less available for stabilization of the radical and anionic intermediates.

It has previously been reported that increasing the chain length of a polysilane leads to a bathochromic shift of the lowest energy UV-visible band, the $\sigma-\sigma^{*}$ transition. ${ }^{10}$ This has been attributed to increased stabilization of the excited state by the longer Si chains. The more positive 
reduction potentials with increasing chain length, which have been previously observed, ${ }^{2}$ also seem to follow the same trend, i.e., that increasing chain length allows for greater stabilization of intermediates over shorter chains. Thus it appears likely that an increase in the stabilization of excited states or electron rich species occurs in oligosilanes with greater $\mathrm{Si}-\mathrm{Si}$ catenation.

The results and interpretations in this paper may have some implications for the mechanism of polysilane formation from dichlorosilanes. ${ }^{10}$ Unfortunately, the best solvents for preparation of Wurtz-coupled polysilanes are hydrocarbons such as toluene, and this is the solvent in which most of the mechanistic studies have been made. ${ }^{22,28-30}$ The normal preparative method is to reflux the appropriate dichlorosilane in toluene with molten $\mathrm{Na}$. If THF is used as a solvent, although high molecular weight polymer is formed initially, it degrades too rapidly to a low molecular weight cyclic material for a real study of the reaction details to be made. Some details of the reaction to toluene are known, but any correlation of the results of such studies in toluene and the electrochemical results in polar solvents must be treated with caution. In toluene the reaction of dichlorosilanes with $\mathrm{Na}$ exhibits an $\mathrm{S}$ shaped reaction curve, with an initially increasing rate, as if comparatively long-lived polymerizing centres are formed slowly from the original dichlorosilane and the Na surface. These are thought to be silyl anions. The subsequent rate determining propagation step appears to be the reaction of these centres with the dichloride for chain extension followed by rapid reaction of the intermediate product with the $\mathrm{Na}$ surface to regenerate the propagating species. The electrochemical studies show that the $\mathrm{E}_{1 / 2}^{1}$ of the HMDSi monomer is higher than that of the polymer chain chloride. Hence it seems unlikely that a radical chain end could displace a chlorine from the original dichlorosilane monomer. The higher value of $\mathrm{E}_{1 / 2}^{2}$ for the chain silyl anion could promote such a displacement. 
The reduction potentials for formation of the radicals and anions are considerably more positive than some researchers have reported, ${ }^{4,7}$ but in-line with other reports. ${ }^{2,9}$ Based now on $\mathrm{E}_{1 / 2}$ values, relatively mild reducing agents may feasibly be used to affect polymerizations. A previous report noted that the use of the biphenyl radical anion in dichlorosilane polymerizations resulted in only cyclic material being formed. ${ }^{31}$ However that species has a very negative reduction potential and thus may be inducing cyclization either through formation of anionic oligomers with chain lengths sufficient for intramolecular cyclization to occur (as in Equation [5]) or be sufficiently potent to cause degradation of any polymer to cyclic oligomers. Preliminary studies in this lab have indicated that milder reducing agents such as the benzoquinone radical anion, $\mathrm{TiCl}_{3}$ and $\mathrm{TiCp}_{2} \mathrm{Cl}$ give rise to polymeric species on reaction with dichlorosilanes.

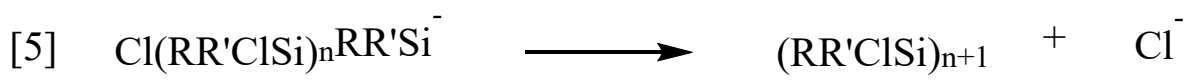

A knowledge of the reduction potentials will also aid in performing electrochemical synthesis of polysilanes. If the potential could be held between the two $\mathrm{E}_{1 / 2}$ values, only radicals will be produced and test whether silyl ion formation is necessary for polymerization. In preliminary studies, we have attempted controlled potential electrolysis with HMDSi in both THF and $\mathrm{MeCN}$ by holding the potential more positive than $\mathrm{E}_{\frac{1}{2}}^{2}$. In both solvents there was evidence of the formation of high molecular weight species (up to $10^{6}$ daltons, although in $\mathrm{MeCN}$ the molar masses were limited by solubility). Electropolymerization using low current densities has been reported to give better yields of polysilanes than higher current densities. ${ }^{15}$ Lower current densities translate into more positive potentials, in keeping with our observations. More work on both chemical and electrochemical polymerization reactions is needed to gain further insights into rates and mechanisms of chloro-containing silane polymerizations. 


\section{Conclusions}

In this work it has been demonstrated that chlorosilanes can be reduced in two one electron steps at potentials more positive than $-1 \mathrm{~V}$ vs SCE. The observed cyclic voltammetric peaks were shown to arise from solvated species and not adsorbed ones. Hydrolysis was determined to be to slow on the time-scale of the experiment and thus not to interfere with the electrochemical measurements. Solvent and electrolyte effects were determined to play a large part in the reduction potentials of the silanes and a model was proposed to account for these effects. The effect of chain length on the ease of reduction is consistent with the red-shifting of the $\sigma-\sigma^{*}$ transition in the UVvisible. The data have implications for polysilane synthesis by both electrochemical and Wurtzcoupling routes.

\section{Acknowledgements}

The authors would like to thank Dr. D. Biro for helpful discussions on electrochemistry and Dr. L. L. Zhou for his experimental help.

\section{References}

(1) Dessy, R. E.; Kitching, W.; Chivers, T. Organometallic Electrochemistry. I. Derivatives of Group IV-B Elements. J. Am. Chem. Soc. 1965, 88, 453-459.

(2) Boberski, W. G.; Allerd, A. L. Properties of Long-Chain Permethylpolysilanes. J. Organomet. Chem. 1975, 88, 65-72.

(3) Allred, A. L.; Bradley, C.; Newman, T. H. Attachment of Permethylpolysilane Groups to Platinum by Electroreduction of Chloropermethylpolysilanes. X-Ray Photoelectron Spectroscopy of Permethylpolysilanes Chemically Bound to Electrode Surfaces. J. Am. 
Chem. Soc. 1978, 100, 5081-5084.

(4) Corriu, R. J. P.; Dabosi, G.; Martineau, M. Re-Examination of the Electrochemical Reduction of Halogeno -Silanes and -Germanes. J. Chem. Soc., Chem. Commun. 1979, $457-458$.

(5) Corriu, R. J. P.; Dabosi, G.; Martineau, M. A Re-Examination of the Electrochemical Reduction of Halosilanes and Halogermanes. J. Organomet. Chem. 1980, 186, 19-24.

(6) Corriu, R. J. P.; Dabosi, G.; Martineau, M. Electrochemical Reduction of TriorganohaloSilanes and Germanes. J. Organomet. Chem. 1980, 188, 63-72.

(7) Hengge, E.; Firgo, H. An Electrochemical Method for the Synthesis of Silicon-Silicon Bonds. J. Organomet. Chem. 1981, 212, 155-161.

(8) Corriu, R. J. P.; Dabosi, G.; Martineau, M. A New Method for the Determination of Water in Organic Solvents and Some Comments on an Electrochemical Method of Synthesizing Si-Si Bonds. J. Organomet. Chem. 1981, 222, 195-199.

(9) Duchek, P.; Ponec, R.; Chválovsky, V. Experimental and Theortical Study of the Electrochemical Reduction of Halosilanes. J. Organomet. Chem. 1984, 271, 101-106.

(10) Miller, R. D.; Michl, J. Polysilane High Polymers. Chem. Rev. 1989, 89, 1359-1410.

(11) El Omar, F.; Geniès, E. M. Electrochimie Des Composes Organiques Du Silicium. Revue Bibliographique. Electrochem. Acta 1983, 28, 541-546.

(12) Yoshida, J. I.; Muraki, K.; Funahashi, H.; Kawabata, N. Electrochemical Synthesis of Organosilicon Compounds. J. Org. Chem. 1986, 51, 3996-4000.

(13) Biran, C.; Bordeau, M.; Pons, P.; Léger, M. P.; Dunoguès, J. L'électrosynthèse, Une Voie 
Simple d'accès Aux Di- et Polysilanes. J. Organomet. Chem. 1990, 382, C17-C20.

(14) Shono, T.; Kashimura, S.; Ishifune, M.; Nishida, R. Electroreductive Formation of Polysilanes. J. Chem. Soc., Chem. Commun. 1990, 1160-1161.

(15) Umezawa, M.; Takeda, M.; Ichikawa, H.; Ishikawa, T.; Koizumi, T.; Fuchigami, T.; Nonaka, T. Electroreductive Polymerization of Organodichloromonosilanes. Electrochim. Acta 1990, 35, 1867-1872.

(16) Umezawa, M.; Takeda, M.; Ichikawa, H.; Ishikawa, T.; Koizumi, T.; Nonaka, T. Electroreductive Polymerization of Mixtures of Chloromonosilanes. Electrochim. Acta 1991, 36, 621-624.

(17) Kunai, A.; Kawakami, T.; Toyoda, E.; Ishikawa, M. Electrochemistry of Organosilicon Compounds. 1. Synthesis of Di- and Trisilanes with Use of Mercury and Silver Electrode Systems. Organometallics 1991, 10, 893-895.

(18) Agrawal, A. K.; Austin, A. E. Electrodeposition of Silicon from Solutions of Silicon Halides in Aprotic Solvents. J. Electrochem. Soc. 1981, 128, 2292-2296.

Gobet, J.; Tannenberger, H. Electrodeposition of Silicon from a Nonaqueous Solvent. $J$. Electrochem. Soc. 1988, 135, 109-112.

(20) Oka, K.; Nakao, R.; Takeyama, T.; Hiraki, K. Reaction of Dodecamethylcyclohexasilane with Thionyl Chloride. Formation of $\alpha, \omega$-Dichloropermethylpolysilanes $\left[\mathrm{Cl}\left(\mathrm{Me}_{2} \mathrm{Si}\right)_{\mathrm{n}} \mathrm{Cl}, \mathrm{n}\right.$ $=2,3,4$, and 6]. Chem. Express 1987, 2, 699-702.

(21) Wojnowski, W.; Hurt, C. J.; West, R. Cyclic Polysilanes IX: The Reaction of Cyclo Permethylpolysilanes. J. Organomet. Chem. 1977, 124, 271-278. 
(22) Worsfold, D. J. Polysilylene Preparations. In Inorganic and Organometallic Polymers; ACS Symposium Series 360; Zeldin, M., Wynne, K. J., Allcock, H. R., Eds.; ACS: Washington, D.C., 1988; pp 101-111.

(23) Bard, A. J.; Faulkner, L. R. Electrochemical Methods, 1st ed.; John Wiley \& Sons Ltd.: Toronto, 1980.

(24) Allen, A. D.; Charlton, J. C.; Eaborn, C.; Modena, G. 724. Nucleophilic Substitution Reactions of Organosiliicon Compounds. Part 1. Reactions of Triisopropylsilyl Chloride. J. Chem. Soc. 1957, 3668-3670.

(25) Chipperfield, J. R.; Prince, R. H. 672. Nucleophilic Substitution at Silicon and Germanium. J. Chem. Soc. 1963, 3567-3573.

(26) Crouch, A. M. Photoelectrochemical and Photocatalytic Behaviour of Thin Porphyrin Films on Semiconductor Materials., Concordia University, 1987.

(27) Fry, A. J. Synthetic Organic Electrochemistry, 2nd Edition, 2nd ed.; Wylie, 1989.

(28) Gauthier, S.; Worsfold, D. J. Mechanistic Studies of Polysilane Polymerization. In Silicon-Based Polymer Science; Advances in Chemistry Vol. 224; American Chemical Society, 1990; pp 299-307.

(29) Gauthier, S.; Worsfold, D. J. The Effect of Phase-Transfer Catalysts on Polysilane Formation. Macromolecules 1989, 22, 2213-2218.

(30) Gauthier, S.; Worsfold, D. J. The Preparation of Polysilyenes. In Inorganic and Organometallic Oligomers and Polymers; Harrod, J. F., Laine, R. M., Eds.; Springer Science, 1991; pp 37-48. 
(31) Zeigler, J. M. Polymer Preprints. Polym. Prepr. 1986, 27, 109. 